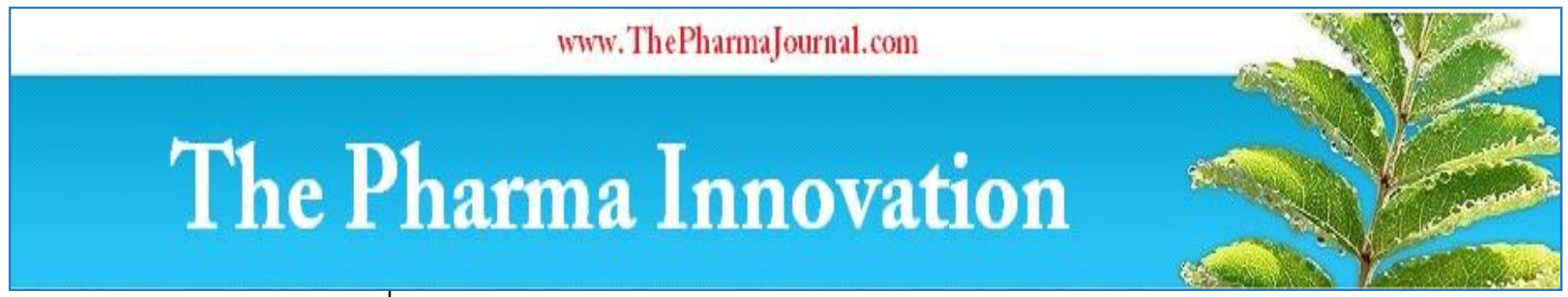

ISSN (E): 2277 - 7695

ISSN (P): 2349-8242

NAAS Rating: 5.03

TPI 2020; 9(11): 285-288

(C) 2020 TPI

www.thepharmajournal.com

Received: 08-09-2020

Accepted: 13-10-2020

\section{K Mahendran}

Professor, Department of

Agricultural and Rural

Management, Tamil Nadu

Agricultural University,

Coimbatore, Tamil Nadu, India

\section{S Moghana Lavanya}

Assistant Professor, Department

of Agricultural and Rural

Management, Tamil Nadu

Agricultural University,

Coimbatore, Tamil Nadu, India

\section{S Praveena}

Teaching Assistant, Department

of Agricultural and Rural

Management, Tamil Nadu

Agricultural University,

Coimbatore, Tamil Nadu, India

\section{Food fortification issues for redressal to attain inclusive promotion of nutritional security: The case of Tamil Nadu State}

\author{
K Mahendran, S Moghana Lavanya and S Praveena
}

DOI: $\underline{\text { https://doi.org/10.22271/tpi.2020.v9.i11e.5348 }}$

\begin{abstract}
Food fortification is one of the important means to reach the unreached in terms of nutritional security. The common deficiency are caused by Vitamin A, Iron and Folic acid. The Government has been making policy interventions for food fortification through various stakeholders. The lack of awareness among the consumers, limited access due to various socio economic factors, apathy of the food processors and private businesses are the major reasons for the poor take-off of the government priorities. This paper attempts to review similar efforts across the globe indicates the importance of acceptance and preference for fortified foods among the rural, urban consumers and the other stakeholders involved in manufacture and distribution of the fortified foods including the government. Food fortification has been proven to be one of the best alternatives to reduce the malnutrition in the population. Given the conditions, it is essential to understand what are the technical/process changes to be newly implemented for the purpose of fortification by the existing millers /manufacturers/ processors in the state in the case of rice, oil, milk and salt. The additions and alterations in the processes require further investment in money, expertise and time further to addressing the other constraints. Their willingness to adopt the new process is a key.
\end{abstract}

Keywords: Fortification, stakeholders, inclusive promotion, awareness, consumers

\section{Introduction}

There is a high level of micro nutrient deficiency caused by Vitamin A, Iodine, Iron and Folic Acid leading to Night Blindness, Goitre, Anaemia and various birth defects among children, and women. Report of National Family Health Survey (2018) indicates that 58.4 percent of children (6-59 months) are anaemic, 53.1 percent women in the reproductive age group are anaemic and 35.7 percent of children under five are underweight. Fortification is a globally proven intervention to address the problems of much prevalent micro nutrient deficiencies in the population.

Though Government of India has been implementing fortification promotional programmes for target groups, the general population lacks awareness and clarity on the need for such measures. On the other hand, the role of organized food sector is limited and there lies a huge share of unorganized sector that lacks such focused nutrition promotion measures to support government initiatives.

Therefore the businesses and private sector engagement related to such food processing initiatives both in organized and unorganized sectors needs regulation as well support measures from the government, institutions, formal and informal agencies and associations apart from creating consumer awareness and improving the demand for fortified food. Inclusive promotion of food fortification includes the rural and urban consumers, the other major stakeholders namely the millers, manufacturers and processors across all the regions of the state.

The major food items in the state of Tamil Nadu that could be fortified for achieving the intended nutritional targets are rice, edible oil, milk and salt which are commonly consumed by the population across all social, cultural and income groups.

\section{Issues}

The governmental efforts in addressing the critical nutritional requirements of the vulnerable groups of the population through fortification may not be sufficient to cover the larger groups of population unless all the stakeholders involved in production, processing, distribution and consumption understand its larger benefits and act in coordination.

\footnotetext{
K Mahendran

Professor, Department of

Agricultural and Rural

Management, Tamil Nadu

Agricultural University,

Coimbatore, Tamil Nadu, India
}

$$
\sim 285 \sim
$$




\section{The major issues flagged with specific reference to Tamil} Nadu state are

- Consumers act as a pulling force down the line of demand ensuring the need for fortification efforts by both the organized and unorganized businesses.

- Awareness about the fortified food among the rural and urban consumers regarding the health benefits

- The current dietary pattern and the share of fortified food and its preference among the consumers

- The role of socioeconomic factors like age, education, income, family size and type, health care spending, etc.,

- A national survey study shows that $76.30 \%$ of Indian households consumed iodized salt adequately whereas Tamil Nadu is the worst performer (61.90\%). Probable reasons for such a low coverage.

- The millers are the primary players in implementing the fortification programmes and their role is critical for successful implementation of such initiatives. What are the impediments and the support measures required from various agencies like the processors, Small Food Business Operators (SFBO) including the government for effective roll down.

- To popularize and promote the consumption of fortified food, it is necessary to create awareness among the consumers, promote the other stakeholders in production, distribution and retailing to participate in the process.

- How to engage the private sector businesses and make them participate alongside the government sector needs a serious analysis.

\section{Literature Review}

An attempt was made to understand the various research work related to the theme of this article was carried out and presented in this section.

Verlegh and Steenkamp (1999) ${ }^{[14]}$ highlighted that consumer decision making is a complex process influenced by many factors. Marketing, branding, and packaging blast consumers with information about a product in order to purposely alter their consumption patterns, choices, preferences.

Ares et al. (2008) ${ }^{[3]}$ found that lack of nutritional knowledge limited the acceptance of functional foods and suggested the need to assure that consumers are aware of the health benefits that are expected from functional foods.

Siro etal (2008) ${ }^{[12]}$ reported that Consumer acceptance of the concept of functional foods has been determined by a host of factors such as primary health concerns, consumers' familiarity with the "functional food" concepts and with the functional ingredients, the nature of the carrier product, the manner of health effect communication, etc.

Mullie et al., (2009) [8] conducted a study on cultural, socioeconomic and nutritional determinants associated with functional food consumption pattern among 5000 military men of Belgium found age, physical activity, level of education, use of vitamin supplements and cultural background are predictors of functional food consumption patterns.

Beinner et al., (2010) ${ }^{[4]}$ opined consumption of fortified rice was found to be associated with significant reductions in anaemia and/or improved iron stores in India in their research on iron fortified rice efficient as supplemental iron drops in infants and young children.

Pounis et al. (2011) ${ }^{[6]}$ reported that Consumer perception on iron fortified foods is associated with nutrition knowledge and highlight the importance of focused nutrition education in consumer informed choices.

Animashaun et al., (2013) [1] while examining consumer perspectives on health benefits and willingness to pay for moringa powder found respondents were willing to pay about $5 \%$ over and above the current price of Moringa product so as to have access to perceived product's Nutraceutical benefits. WTP was found to be significantly influenced by perception of efficacy of product's benefits, education and occupation of respondents.

Buyuk kargoz et al. (2014) investigated the consumers awareness, acceptance, and attitude towards functional food in turkey and the result of the study indicated that socio demographic characters influenced the consumer awareness. The study also posited that consumer with high level of university education were more likely to consume probiotic and cholesterol lowering products. In organophilic attributes, taste is the most important factor that affected consumer's choice.

Jain et al. (2014) ${ }^{[11]}$ has evaluated consumer behaviour and attitudes regarding the consumption of functional food and measured consumer willingness to pay for functional foods containing special health claims. Consuming less fat and eating more vegetables and fruits has increasingly become food habit of the respondents owning to lifestyle changes.

Vecchio et al., (2016) ${ }^{[13]}$ investigated consumer's willingness to pay for conventional organic and functional yogurts in two different information treatments to 100 Italian consumers. Findings revealed that providing additional information through a specific health claim increases consumer's perceived value of the functional yogurt, while for the organic counterpart additional information on organic regulation does not add much to the premium. Moreover, specific sociodemographic variables (as gender, age, presence of kids in the household and the need to follow a specific diet) positively affect WTP for functional and organic yogurts.

Shamal and Mohan (2017) [10] identified factors such as consumer awareness, nutrition labelling etc that influenced the consumer acceptance towards fortified foods and beverages and proposed a integrated FFB acceptance model for the Indian health food market.

Rekha and Chawan (2017) ${ }^{[9]}$ in their work on awareness and consumption of fortified foods among adult consumers in Mumbai found the attitude of respondents towards consumption of fortified foods was mainly due to health benefits and affordable prices.

Anjuli et al., (2018) ${ }^{[2]}$ in their review on food fortification a nutritional management strategy in India concluded that even though trials conducted with fortified foods in India mostly were found having positive results to improve the nutritional status there is sufficient scope and necessity to broaden the trial design including the population of different age groups and socioeconomic status with special emphasis on female of childbearing age and geriatric population.

FSSAI implemented the food safety and standards (fortification of food) regulations in 2016 with guidelines for staples. According to Chery (2018), 110 brands belonging to the five fortified staple products have been introduced in the market. According to Shepherd (1989), acceptance of food is basically the result of the interaction between food and man at certain moment. Food acceptability is affected by many factors, which may be related to the individual, the food, or the environment in which the food is consumed. There are several factors affecting consumer food choice, including price, taste, income, and attitudes towards different food 
issues. Review of the past literature indicates the importance of acceptance and preference for fortified foods among the rural, urban consumers and the other stakeholders involved in manufacture and distribution of the fortified foods including the government. Food fortification has been proven to be one of the best alternatives to reduce the malnutrition in the population.

\section{Case of Tamil Nadu State}

Tamil Nadu has a total population of 7.21 crores and child population of 7,423,832. Severe Acute Malnutrition (SAM) is high among children (under the age of five) and around $8 \%$ of children in Tamil Nadu are severely malnourished. At least 20,000 children under the age of six in Tamil Nadu are so severely malnourished that their growth can be permanently tunted. About 20,593 of the 41.52 lakh children weighed in Anganwadi across the state are classified under the category of SAM, which means their actual body weight is less than $50 \%$ of the ideal body weight. Only $31 \%$ children get adequate nutrition in Tamil Nadu (KHPT Fact Sheet, 2018).

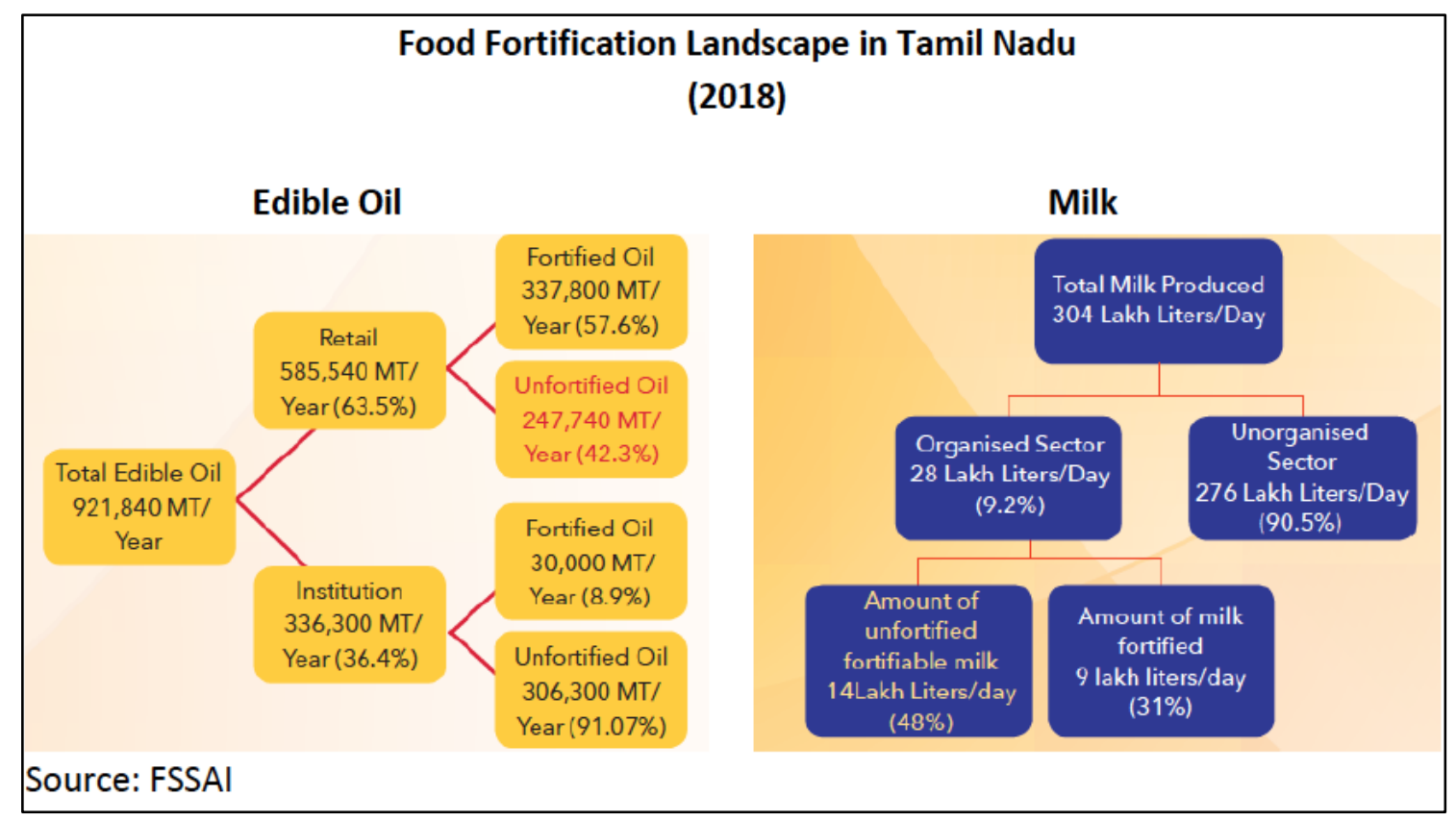

Fig 1: Food Fortification Landscape in Tamil Nadu

Out of 9.22 lakh tonnes of total edible oil manufactured in Tamil Nadu state, 5.54 lakh tonnes $(60 \%)$ are unfortified. In the case of milk, out of the total milk production of 304 lakh litres per day, about 290 lakh litres are unfortified as majority production lies with the unorganized sector.

Tamil Nadu has the lowest consumption of Iodised salt in the country despite being the third largest producer of salt in the country. The highest per cent of households covered was $99.80 \%$ in case of Jammu and Kashmir against the national average of $76.30 \%$ where as it was only $61.90 \%$ in the case of Tamil Nadu (Nutrition International Survey, 2019).

In this direction, the fact that the government initiatives alone cannot bring an effective change needs a serious analysis on engagement and participation of the organized and unorganized businesses in promoting the use of fortified food as a means to address the issue of malnutrition. The awareness, reach, acceptance and use by the consumers equally play an important role in addressing the issue.

\section{Conclusion}

Various studies have pointed that consumer acceptability is influenced by factors such as knowledge, attitude, food choice behaviour, culture, lifestyle, consumer perception etc. Technologies differ with regard to how nutrients are fortified with the target commodity, required investment, production cost, and degree of resemblance to unfortified counterparts. Some of the main roadblocks appear to be high initial investment and associated cost; lack of government leadership; and consumer hesitation to accept variations in the characteristics of fortified food, or a higher price, without good understanding of the benefits. The millers/manufacturers /processors play a key role in taking forward the fortification agenda promoted by the government. Despite the presence of regulations and governance, the onus of implementing the fortification to its full effect relies on them.

Given the conditions, it is essential to understand what are the technical/process changes to be newly implemented for the purpose of fortification by the existing millers /manufacturers/ processors in the state in the case of rice, oil, milk and salt. The additions and alterations in the processes require further investment in money, expertise and time further to addressing the other constraints. Their willingness to adopt the new process is a key.

\section{References}

1. Animashaun JO, Williams FE, Toye AA. Towards Validating Moringa's Nutraceutical Benefits: Examining Consumers' Perspectives vis-à-vis Health Satisfaction and Willingness to Pay. Journal Agris on-line Papers in Economics and Informatics 2013;5(2):11-21.

2. Anjuli Sirohi, Aditya Pundhir, Sampat Ghosh. Food Fortification: A Nutritional Management Strategy in India, Innovare Journal of Food Sci 2018;6(2):1-8.

3. Ares Gastón, Ana Giménez, Adriana Gámbaro. Understanding consumers' perception of conventional and functional yogurts using word association and hard laddering. Food Quality and Preference Volume 19, Issue 7, October 2008, Pages 636-643

4. Beinner MA, Velasquez-Mele'ndez G, Pessoa MC, Greiner T. Iron-Fortified Rice Is As Efficacious As 
Supplemental Iron Drops in Infants and Young Children. The Journal of Nutrition 2010;140(1):49-53.

5. Brian Wansink, Koertvan Ittersum, James E Painter. How descriptive food names bias sensory perceptions in restaurants. Food Quality and Preference. Volume 16, Issue 5, July 2005, 393-400.

6. George D Pounis, Stella Makri, Lazaros Gougias, Haralambos Makris, Marianna Papakonstantinou Demosthenes B Panagiotakos, et al. Consumer perception and use of iron fortified foods is associated with their knowledge and understanding of nutritional issues. Food Quality and Preference 2011;22:683-688

7. khptblr@khpt.org

8. Mullie P, I Guelinck, P Clarys, E Degrave, M Hulens, G Vansant, et al. Cultural, socioeconomic and nutritional determinants of functional food consumption patterns, European Journal of Clinical Nutrition 2009;63:12901296.

9. Rekha Battalwar, Akshata Paresh Chavan. A Study on Awareness and Consumption of Fortified Foods among Male Adults of Mumbai. Int. J. Adv. Res. 2017;5(11):403-413.

10. Shamal S, Bijuna C Mohan. Consumer behaviour in fortified food choice decisions in India", Nutrition \& Food Science 2017;47(2):229-239,

11. Shikha Jain, Kirti Sharma, Mansi Khadke. Consumer Behaviour toards Functional Foods in India - A Study of Market Drivers and Challenges.IOSR Journal of Business and Management (IOSR-JBM) 2014. e-ISSN: 2278487X, p-ISSN: 2319-7668 33-40.

12. Siro Istvan, Emese Kapolna, Beáta Kápolna, Andrea Lugasi. Functional Food. Product Development, Marketing and Consumer Acceptance-A Review. Appetite 2008;51(3):456-67.

13. Vecchio Riccardo, Van Loo, Ellen J, Annunziata Azzurra. Consumers' willingness to pay for conventional, organic and functional yogurt: evidence from experimental auctions, International Journal of Consumer Studies; Oxford 2016;40(3):368-378.

14. Verlegh PWJ, JBEM Steenkamp. A review and metaanalysis of country-of-origin research, Journal of economic psychology, 1999 - Elsevier 1999. 